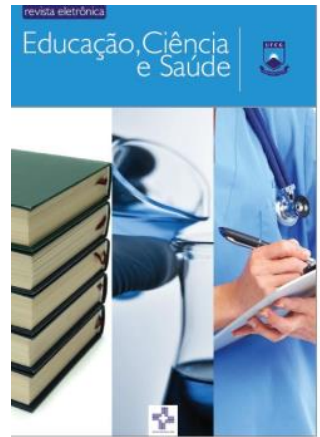

EDUCAÇÃO CIÊNCIA E SAÚDE

http://dx.doi.org/10.20438/ecs.v7i1.257

\title{
HABILIDADES EMPREENDEDORAS DE CONCLUINTES DO CURSO DE ENFERMAGEM DE UMA INSTITUIÇÃO DE ENSINO SUPERIOR
}

\author{
Jaysa Soares dos Santos ${ }^{1}$, Joane Paloma de Souto Araújo ${ }^{1}$, Amélia Raquel Lima de \\ Pontes $^{1}$, Nathanielly Cristina Carvalho de Brito Santos ${ }^{2}$, Matheus Figueiredo \\ Nogueira², Luciana Dantas Farias de Andrade ${ }^{2}$ \\ ${ }_{1}$ Curso de Bacharelado em Enfermagem, Unidade Acadêmica de Enfermagem, Universidade Federal \\ de Campina Grande, Cuité-PB, Brasil. \\ 2 Professores da Unidade Acadêmica de Enfermagem, Universidade Federal de Campina Grande, \\ Cuité, PB, Brasil. \\ E-mail para correspondência: jaysasoares@hotmail.com
}

\begin{abstract}
Resumo
O objetivo desta pesquisa foi identificar as habilidades empreendedoras dos concluintes do curso de bacharelado em enfermagem de uma Instituição de Ensino Superior. Estudo de abordagem qualitativa, descritivo e exploratório, realizado entre agosto e setembro de 2018. Participaram 24 discentes de uma população composta por 43, que se enquadravam na condição de concluintes do curso de bacharelado em enfermagem de um campus em expansão. Os dados foram coletados por meio de entrevistas, atentendo à disponibilidade de cada estrevistado. A análise de discurso aconteceu em etapas sendo elas transcrição, análise prévia e interpretação. Os resultados apontaram que os concluintes apresentam o conceito midiático do empreendedorismo, mesmo cursando disciplinas voltadas para a temática em sua futura profissão. Limitam suas visões as opções de empreendedorismo coorporativo em detrimento ao social, e não demonstram desejo em empreender, apontando predileção por opções estáveis para iniciar a carreira profissional. Pôde-se concluir que os entrevistados apresentavam traços de habilidades empreendedoras, no entanto, era nítida a timidez evidenciada pela citação estratégica em terceira pessoa aliada ao pensamento de atuação hospitalocentrico, mesmo a enfermagem sendo uma área em ascensão no empreendedorismo e com diferentes possibilidades laborais.
\end{abstract}

Palavras-chave: enfermagem, gestão em saúde, mercado de trabalho.

\begin{abstract}
The objective of this research was to identify the entrepreneurial skills of those graduating from the nursing bachelor's course at a Higher Education Institution. Qualitative, descriptive and exploratory study, carried out between August and September 2018. 24 students from a population composed of 43 participated, who were graduating from the nursing bachelor's course in an expanding campus. Data were collected through interviews, taking into account the availability of each interviewee. The discourse analysis happened in stages, being transcription, previous analysis and interpretation. The results
\end{abstract}


showed that the graduates present the media concept of entrepreneurship, even taking courses focused on the theme in their future profession. Their views limit the options of corporate entrepreneurship to the detriment of social entrepreneurship, and do not demonstrate a desire to undertake, pointing to a predilection for stable options to start their professional careers. It can be concluded that the interviewees showed traces of entrepreneurial skills, however, the shyness evidenced by the strategic quote in third person coupled with the thought of hospitalocentric performance was clear, even though nursing is an area on the rise in entrepreneurship and with different work possibilities.

Keywords: nursing, health management, job market.

\section{Introdução}

Diante dos desafios impostos no atual cenário do mercado de trabalho, os profissionais devem estimular ainda mais suas competências e habilidades, a fim de transformar oportunidades e vislumbrar não apenas uma única direção, mas sim, um arsenal de atrativos tornando o empreendedorismo uma ferramenta importante no desenvolvimento regional e no crescimento das economias (RIBEIRO et al., 2016).

Nessa perspectiva, empreender significa observar oportunidades e inovar permanentemente a fim de compreender as novas possibilidades diante das mudanças no mercado, ou mesmo aliar habilidades frente aos constantes desafios, a fim de obter satisfação profissional, pessoal e financeira, contribuindo para a consolidação de um caráter evolutivo e emancipatório, não apenas exclusivo da enfermagem ou, especificamente, de qualquer campo de conhecimento da área de saúde, mas de um fenômeno mundial de adaptação a um movimento cíclico econômico que interfere na economia mundial (SILVA; VALENTE; VALENTE, 2017; POLAKIEWICZ et al., 2013).

A enfermagem vem se reformulando como profissão através dos anos e criando condições de gerar ações que modifiquem suas ações em uma realidade potencialmente lucrativa e inovadora. No entanto, essa possibilidade de reinvenção requer habilidades imprescindíveis para o desenvolvimento de uma atitude empreendedora e, nesse sentido, a enfermagem carrega em sua história grandes exemplos de perfis empreendedores como Florence Nightingale, Anna Nery e Wanda Horta que revolucionaram a enfermagem através das habilidades e competências que até hoje são estudadas e exercidas (MOURA; BRUM, 2017; COSTAS et al., 2013).

Estudar as habilidades empreendedoras dos graduandos em enfermagem pode demonstrar diferentes escolhas quando futuros profissionais, pois alguns acadêmicos podem verbalizar uma visão ampliada, vislumbrando as diversas 
possibilidades que o (a) enfermeiro (a) pode atuar no mercado de trabalho, enquanto outros apenas se limitarão à atuação em âmbito hospitalar, atenção primária e docência.

Assim, justifica-se este estudo em face da relevância temática. Neste sentido, tem-se a seguinte questão norteadora: "Quais as habilidades empreendedoras dos acadêmicos de enfermagem acerca das estratégias que possam implementar quando enfermeiros, no mercado de trabalho?" Este estudo teve como objetivo identificar as habilidades empreendedoras dos concluintes do curso de bacharelado em enfermagem de uma Instituição de Ensino Superior.

\section{Metodologia}

\subsection{Desenho do estudo}

Estudo de abordagem qualitativa, descritivo e exploratório, cujo principal objetivo é interpretar o fenômeno de observação, visando observar a palavra (falada, escrita, simbólica) que expressa os comportamentos humanos e permite a análise dos significados. Ancora-se no prisma teórico metodológico do Materialismo Histórico Dialético (MHD) que, dentre outros princípios, trabalha a contradição por entender que para pensar a realidade é preciso elucidar os extremos, para se aproximar do essencial, ou seja, partindo do empírico, do real aparente, avançando para reflexões, teorias e abstrações, sendo possível o acesso à essência daquela realidade (MINAYO, 2017).

\subsection{Cenário}

O cenário foi um campus em expansão da Universidade Federal de Campina Grande, localizado no município de Cuité, Paraíba, que oferta os cursos de licenciatura em Biologia, Matemática, Física e Química, além dos cursos de bacharelado em Enfermagem, Farmácia e Nutrição.

\subsection{Sujeitos da pesquisa}

Neste sentido, o foco do estudo foi o Curso de Bacharelado em Enfermagem, considerando a opinião de concluintes dos semestres letivos 2018.1 e 2018.2. A 
coordenação do curso disponibilizou uma lista contendo uma população equivalente ao total de 43 alunos concluintes, desses, 24 compuseram a amostra final.

\subsection{Critérios de seleção}

Os critérios de inclusão foram: ter idade superior a 18 anos, estar regularmente matriculado no sistema de informação da Instituição de Ensino Superior, encontrarse nos dois últimos semestres do curso e ter cursado as disciplinas "Gestão em Enfermagem I", "Bases Teóricas da Gestão em Enfermagem II" e "Bases Práticas da Gestão em Enfermagem II".

Dessa forma, por motivos pessoais, metodológicos ou de outra natureza foi respeitado a decisão de não participação de alguns estudantes perfazendo uma amostra de 24 acadêmicos, escolhidos por disponibilidade e respeitando-se os princípios éticos da resolução 466/2012 para a execução da pesquisa com seres humanos (BRASIL, 2012).

Observou-se o perfil dos graduandos, segundo dados pessoais e acadêmicos. Dessa forma, no tocante à idade, dos 24 entrevistados nove encontram-se na faixa etária entre 21 a 23 anos, 14 tem entre 24 a 27 anos e apenas 1 tem 29 anos. De acordo com o sexo houve predominância do sexo feminino, com 15 estudantes. Quanto ao estado civil, há predomínio de solteiros com 23 sujeitos. Em relação à existência de filhos, 24 não tem filhos. Quando perguntados quanto às outras formações acadêmicas de nível médio ou superior 17 não possuem outra formação acadêmica e 7 verbalizaram outra formação em técnico de enfermagem, técnico em saúde bucal, eletrônica e eletrotécnica. Um aluno relatou ser formado em ciências contábeis. Para religião, 17 se denominaram católicos, 03 sem religião, 03 evangélicos e 01 cristão.

\subsection{Coleta de material empírico}

A coleta de material empírico foi realizada entre os meses de agosto e setembro/2018 após aprovação projeto pelo Comitê de Ética em Pesquisa da Universidade Federal de Campina Grande, sob o protocolo de pesquisa 끄 2.794 .996 e CAAE no 87939218.2.0000.5182. 
Para assessorar a investigação, foi elaborado um roteiro semiestruturado, composto por duas partes. A primeira parte trata dos dados sociodemográficos e de perfil: "iniciais do nome", "idade", "sexo", "genêro", "estado civil", "logradouro", "religião", "filhos", em resposta afirmativa, "quantos filhos?", "-Tem formação em outro(s) curso(s)?".

A segunda parte contém questões acerca de projeções para enfermagem no atual cenário econômico, além de questionamentos sobre desafios, iniciativas e oportunidades de negócios, a fim de ampliar e explorar ao máximo os depoimentos: "-Explane o que você sabe sobre empreendedorismo"; "-Que iniciativa você teria ao se deparar com uma situação complicada no ambiente de trabalho? Justifique sua resposta". Na oportunidade também era questionado: "-Quais as iniciativas dos entrevistados frente às situações desafiadoras do ambiente acadêmico" como pergunta complementar.

Respeitando o enfoque qualitativo do Materialismo Histórico Dialético. Após a assinatura do Termo de Consentimento Livre e Esclarecido (TCLE), e entregue uma via ao participante, eram realizadas as entrevistas em horário e local previamente marcados, atendendo à disponibilidade do entrevistado, com gravação do áudio em aparelho do tipo MP3, sem delimitar tempo para que a entrevista se desse no ritmo do entrevistado, variando entre 10 e 15 minutos. Em outro momento e local realizava-se a transcrição, juntamente com a organização dos dados sociodemográficos na íntegra e no mesmo dia, a fim de reduzir falhas.

\subsection{Análise e tratamento do material empírico}

Para assegurar o sigilo das informações, os depoentes foram enumerados do "1" ao "24", conforme a sequência das entrevistas, e identificados pela letra " $E$ ".

A organização começou com a transcrição na íntegra dos depoimentos dos entrevistados, no mesmo dia em que as entrevistas eram realizadas. Depois passamos para a parte da análise prévia, quando havia repetidas leituras da transcrição com separação dos trechos dos entrevistados. Cada trecho apresentava um tema que foi decodificado de acordo com a interpretação do pesquisador.

Os temas decodificados formaram blocos de significação em que foi possível codificar os temas semelhantes, desta forma, foi possível interpretar, pela técnica de análise de discurso de Fiorin, a compreensão abstrata das habilidades 
empreendedoras expressa pelos estudantes por meio das categorias empíricas (FIORIN, 2005).

\section{Resultados e discussão}

A técnica de análise de discurso de Fiorin permitiu a construção de duas categorias empíricas: "O conhecimento prévio sobre empreendedorismo como fator sinalizador para habilidades empreendedoras"; e "Analisando habilidades para a resolução de desafios e obstáculos diários".

\subsection{Categoria Empírica 1: O conhecimento prévio sobre empreendedorismo como fator sinalizador para habilidades empreendedoras}

Habilidades são qualidades ou características que uma pessoa pode ter frente a determinado objetivo, enquanto empreendedorismo não tem um conceito único, mas pode-se dizer que é a capacidade de ser, ter e fazer acontecer determinado projeto como desafio constante. Para empreender é necessário um conjunto de habilidades, e essas podem ser trabalhadas e potencializadas academicamente (CARREIRA et al., 2015). Os fragmentos de fala em destaque expressam o entendimento dos entrevistados sobre empreendedorismo, enfatizando habilidades e competências do perfil empreendedor.

É uma área que você oferta algum serviço, algum trabalho, algum produto que a pessoa venha buscar, o que pode ser um spa, uma terapia complementar, vender materiais como jaleco, estetoscópio e outros materiais (E9).

Empreendedorismo é uma visão que vai mais além do que um emprego formal numa instituição, é você ter ideias inovadoras, principalmente em se tratando da enfermagem (E10).

Bom, empreendedorismo para mim é você investir em algo, tanto em ideias, quanto em materiais e no ambiente trazendo melhorias para a população, seja no caso em enfermagem relacionada a feridas ou estética que hoje é o que está aí bem atual no mundo e em outras áreas também como geriatria e pediatria (E15). 
É possível elucidar nos depoimentos que os graduandos apresentam o conceito midiático do que seja empreendedorismo, mesmo cursando disciplinas voltadas para a administração e gestão em serviços de saúde e enfermagem. Embora tenham capacidade para apresentar 0 conceito teórico de empreendedorismo para exemplificar fatos corriqueiros da realidade no intuito de expressar o entendimento do tema.

Apesar desse distanciamento nos depoimentos envolvendo o conceito de empreendedorismo, faz-se importante salientar que os acadêmicos que participaram da pesquisa tiveram contato com a temática nas disciplinas "Bases Teóricas da Gestão em Enfermagem II" e "Bases Práticas da Gestão em Enfermagem II", pois o plano de curso apresenta um item referente ao tema com prática realizada através de uma visita técnica a um empreendimento do município de Cuité administrado por uma enfermeira egressa da Instituição de Ensino Superior.

As falas expressam habilidades que podem ser desenvolvidas por empreendedores como as baseadas no modelo de Durham que considera as habilidades empreendedoras: necessidade de realização, criatividade, impulso, autonomia e coragem para assumir riscos calculados/moderados, no entanto, os acadêmicos expressam tais habilidades na terceira pessoa, de maneira a não se incluir no rol dos empreendedores. Isso leva a crer que, mesmo demonstrando conhecimento do tema, não se enxergam no papel de empreendedores e não demonstram que irão praticar tais habilidades futuramente, no mercado de trabalho, mesmo faltando seis meses a um ano para isso (SILVA; VALENTE; VALENTE, 2017).

Os fragmentos de fala a seguir expressam uma visão voltada excepcionalmente para o empreendedorismo corporativo, em contrapartida, a enfermagem é reconhecida por sua longa trajetória desenvolvendo o empreendedorismo social que é voltado aos problemas sociais e a produção de benefícios para o indivíduo e comunidade.

O ato de empreender, na minha opinião, é quando você não tem medo de se jogar no escuro e ver os resultados financeiros a curto e a longo prazo chegarem. Empreendedor é a pessoa que tem a capacidade de pensar, de criar, de recriar, de se sustentar em uma linha fina e se fazer diferente em relação aos demais (E21). 
Empreendedorismo é a capacidade que você tem de colocar em prática suas ideias, a sua criatividade naquilo que você quer lucrar, naquilo que você tenha fins lucrativos (E23).

O empreendedorismo é dinâmico, não se limitando como um fenômeno exclusivamente econômico e corporativista. Dentre as diferentes abordagens empreendedoras vale ressaltar o empreendedorismo social que é voltado ao desenvolvimento de atividades que unem o conhecimento técnico-científico e o saber popular, permitindo a transformação de realidades. Nesse contexto, é evidente a importância de um olhar horizontalizado por parte dos futuros profissionais, pois a enfermagem pode atuar com múltiplas abordagens no empreendimento de sua assistência (BACKES et al., 2015).

Observa-se, portanto, que os entrevistados sinalizam nas falas que tem familiaridade com o tema, visto apresentarem conceitos convergentes com a literatura, porém, enfatizam o empreendedorismo corporativo que, no contexto social capitalista, prevalece às trocas por unidades monetárias, e a enfermagem está tendo destaque neste contexto através de empresas que oferecem assistência de enfermagem visando o lucro e têm apresentado resultados positivos. No entanto, apesar do aumento da visibilidade, a possibilidade de torna-se enfermeiro empreendedor ainda é restrita seja por insegurança, falta de habilidades ou mesmo de recursos financeiros (COPELLI; ERDMANN; SANTOS, 2019).

Diante disso, é importante tornar evidente que o mercado de trabalho não se limita apenas à atuação como autônomos ou donos de estabelecimentos assistenciais de saúde, mas, sobretudo no cuidado ao cliente em qualquer contexto, seja atenção primária, secundária, terciária, público ou privado, que converge para a atuação concomitante do empreendedorismo social e empreendedorismo corporativo. Tais processos e possibilidades capacitam o futuro profissional na elaboração de novas estratégias empreendedoras, seja na prática assistencial ou em qualquer outra (VITAL; AMA; ASSIS, 2018).

Dessa forma, é plausível considerar que os conceitos trazidos pelos entrevistados sofrem uma forte influência midiática, local-cultural e familiar propiciado por conversas e depoimentos que levam a crer que, mesmo diante de tantas influências, as realidades podem ser transformadas: a enfermagem está sendo vista em seu aspecto empreendedor. 


\subsection{Categoria empírica 2: Habilidades empreendedoras diante de desafios}

Empreender é ser capaz de protagonizar novos campos e práticas de atuação profissional e para alcançar seus objetivos, o empreendedor cria processos inovadores, planejar e fixar metas com foco em alcançá-las. Assim, o desenvolvimento das habilidades empreendedoras torna-se um estímulo para 0 acadêmico refletir acerca de possibilidades infinitas e comumente obscuras (ANDRADE, DAL BEN, SANNA, 2015).

$\mathrm{Na}$ enfermagem, assim como em qualquer outra ciência, o empreendedorismo requer habilidades como: ação, organização, criatividade, autonomia e outras. E tais habilidades podem ser estimuladas, por meio do estudo e da prática e essa é uma particularidade do empreender, que ao assumir riscos com criatividade instiga a autonomia, o que demonstra que habilidades podem ser estimuladas, quando trabalhadas durante a prática profissional (CARVALHO, 2016).

Diante do exposto, o profissional de enfermagem dificilmente estará isento de problemas e, nesse contexto profissional, as habilidades empreendedoras são decisivas durante a tomada de decisão gerada por alguma situação pontual. Assim, questionados sobre qual atitude tomariam diante desse provável problema de trabalho nos fragmentos elencados.

Primeiro eu tenho que entender o que está acontecendo de uma forma geral, e segundo eu tenho que procurar entender qual a minha parcela de responsabilidade nisso, só então depois de que eu enxergar o problema e o que eu posso fazer com aquilo, é que vou saber o que posso fazer. Se vou procurar ajuda, se eu posso resolver sozinha, mas nada deve ser resolvido de maneira imediata, como se diz assim, na força da raiva ou no estresse, tudo tem que ser pensado e analisado. (E6)

Primeiro, eu iria observar bem o contexto no qual eu estaria inserido e tentaria conversar com as pessoas envolvidas, pois toda história tem mais de uma versão, então, procuraria saber todas as versões e eu utilizaria do meu conhecimento científico e da minha prática para tomar a decisão mais correta, respeitando todos. (E13) 
Como iniciativa eu teria que tentar mostrar o meu potencial e buscar melhorar as dificuldades que o mercado tem, tentando superá-las e mostrando todo o potencial, e capacidade (E17).

Se eu não souber resolver irei buscar ajuda de alguém que pudesse me auxiliar (E20).

Diante de uma situação complicada a gente tem sempre que saber lidar com ela, seja no ambiente de trabalho ou em uma sala de aula a gente tem que sentar, averiguar a situação e buscar uma melhor forma de se sair bem diante dela (E23).

Empreender requer habilidades dinâmicas que dialoguem entre si para que o processo laboral possa ser praticado de maneira que os obstáculos sejam superados através de planejamento, organização, visualização de metas que possam ser cumpridas, mesmo que envolvam sacrifícios pessoais. O empreendedor entende que determinados sacrifícios pessoais poderão ser recompensados, pois sempre se vislumbra um futuro próspero (CARREIRA et al., 2015).

Estimulados a imaginar-se diante de uma situação complicada onde precisasse superar algum obstáculo destacam-se posturas convergentes com habilidades empreendedoras. Cenários desafiantes são comuns em diferentes âmbitos de atuação da enfermagem e diante de desafios cotidianos habilidades como criatividade, ousadia, autonomia, necessidade de realização endossam como sendo particularidades, que para alguns pode estar intrínseca, mas para outros será necessário um estímulo (CHAGAS, et al., 2018).

Diante das falas é perceptível que os entrevistados não se apresentam confortáveis para tratar do assunto, não se sentiram confiantes para expressar o enfrentamento de desafios do próprio cotidiano, situações em que vislumbrassem obstáculos significativos que pudessem ser compartilhados na entrevista, mesmo quando o entrevistador não limita e o deixa livre para compartilhar situações do cotidiano acadêmico, os desafios em ser estudante, os trabalhos em grupo nas disciplinas teóricas, as divisões da escala no Estágio Supervisionado no contexto hospitalar. Enfim, entende-se que os entrevistados não quiseram se expor para descrever minuciosamente os próprios desafios enfrentados cotidianamente e como tentam resolvê-los. 
Compete ainda salientar que os mesmos têm ciência de que algumas técnicas conduzem a habilidades e competências empreendedoras, como organização, delimitação de metas, prazos, procurar recursos humanos competentes para esclarecimentos e assumir riscos calculados. No entanto, existe uma certa resistência quanto ao assunto.

Mesmo o empreendedorismo na enfermagem sendo uma realidade, a maioria dos entrevistados não se descrevem como empreendedores e não expõem iniciativas propriamente ditas como a abertura de empresas para tratamento de feridas, assistência de enfermagem ou similares, ONGs, movimentos sociais ou até buscar aperfeiçoar-se no mercado de trabalho antes de abrir o próprio negócio e esse fato pode ser explicado pela cultura médico-centrada de assistência hospitalar, pelo incentivo limitado durante toda graduação, quando o ideal seria que todas as disciplinas abordassem, mesmo que de forma compactada, o empreendedorismo a fim de formar profissionais mais seguros e visionários com competências e habilidades voltadas ao mercado de trabalho cada vez mais diversificado (COLICHI; LIMA, 2018).

A insegurança apresentada pelos graduandos também pode ser influenciada pela instabilidade do cenário sociopolítico e econômico, evidenciada pelas tentativas de desmontes de direitos sociais em saúde, educação, meio ambiente e outros. Nessa conjuntura, é possível citar determinações como a emenda constitucional 95 que congela e corta gastos públicos destinados à saúde e educação, a nova política da atenção básica que altera e limita atribuições e ações dos profissionais, a reforma trabalhista, que amplia os direitos das empresas e reduz os direitos trabalhistas. Essas transformações vêm violar a democracia e os direitos sociais já conquistados, colocando em risco o SUS com o estímulo à privatização e colocando em risco a empregabilidade no setor público podendo afetar substancialmente a maior força de trabalho em saúde no Brasil (BOLINA, 2019; CASTRO et al., 2019)

Todavia, mesmo diante de um universo dinâmico de possibilidades e cada vez mais limitado ao funcionalismo público, preocupa que o futuro enfermeiro apresenta predileção por opções estáveis para iniciar sua carreira profissional. Empreender ainda se apresenta como opção distante, tomada por barreiras e uma delas envolve o despreparo para o enfrentamento às estruturas tradicionais do mercado de trabalho que apresentam desvalorização profissional, baixa remuneração financeira e alta carga horária laboral, que faz com que os sujeitos dessa pesquisa não se 
vejam estimulados a pensar de forma ampla, limitando-se a sua escolha por concursos públicos (JAHANI et al., 2016).

O empreendedorismo e suas habilidades ainda são considerados desafios a serem enfrentados, principalmente pelas instituições educacionais que, pela legislação vigente, através das Diretrizes e Bases da Educação Nacional para os Cursos de Graduação em Enfermagem, Resolução ํo 03/2001, podem ampliar o acesso ao conteúdo nos planos de ensino pela atualização da Matriz Curricular dos cursos. (COLICHI; LIMA, 2018; JAHANI et al., 2016).

\section{Conclusão}

$\mathrm{Na}$ medida em que se estuda o empreendedorismo pode-se perceber o quanto ele está conjugado ao contexto sócio-político-econômico que, em tempos de crise econômica e política, podem oferecer uma possibilidade nova aos futuros enfermeiros. No entanto, fazer acontecer às ideias é indubitavelmente a maior dificuldade nos dias atuais.

A análise de discurso revelou que os entrevistados têm consciência da temática, mesmo que não transmita de forma clara, o que se deve a fatores como a difusão midiática, contexto sociocultural, econômico, entre outros.

Mesmo diante de um ambiente que pouco estimula atitudes empreendedoras, fica evidente nos depoimentos traços de habilidades como: necessidade de realização, criatividade, impulso, autonomia, coragem para assumir riscos calculados/moderados, no entanto, ainda os expressa de forma tímida inclusive citando estratégias em terceira pessoa, o que leva a crer que eles não se veem como potenciais empreendedores, apesar da enfermagem ser uma área em ascensão e com diferentes possibilidades.

Mesmo diante de um histórico positivo para empreendedorismo social, a visão que predomina é exclusivamente do empreendedorismo corporativo.

Pode-se, então, concluir que as habilidades devem ser estimuladas em qualquer contexto. Aqui destaca-se a enfermagem por ser uma área em ascensão e rica em possibilidades. No entanto, torna-se necessário o desenvolvimento de mais estudos durante a graduação que desenvolvam a temática para que os futuros profissionais adquiram uma nova postura e, dessa forma, difunda 0 empreendedorismo na enfermagem como mais uma possibilidade no mercado de 
trabalho, desmistificando a crença de que a enfermagem está limitada ao contexto médico-hospitalar.

\section{Referências}

ANDRADE, Andreia de Carvalho; DAL BEM, Luiza Watanabe; SANNA. Maria Cristina. Empreendedorismo na Enfermagem: panorama das empresas no Estado de São Paulo. Rev Bras Enferm, v.68, n.1, p.40-4, 2015. Disponível em: http://www.scielo.br/pdf/reben/v68n1/0034-7167-reben-68-01-0040.pdf Acesso em: 30 out. 2018.

BACKES, Dirce Stein et al. Atividades socialmente empreendedoras na enfermagem: Contribuições à saúde/viver saudável Escola Anna Nery Revista de Enfermagem, v. 20, n. 1, p. 77-82, 2016. Disponível em: https://www.redalyc.org/articulo.oa?id=127744318011. Acesso em: 24 de mai. 2020.

BOLINA, Alisson Fernandes. A Enfermagem no contexto sociopolítico e econômico contemporâneo: estímulo ao empreendedorismo privado e/ou fortalecimento do empreendedorismo social?. Rev Enferm Atenção Saúde [Online], v. 8, n. 1, p. 1-3, Jan/Jul., 2019.2 Disponível em: http://seer.uftm.edu.br/revistaeletronica/index.php/enfer/article/view/3898/pdf. Acesso em: 26 de mai. 2020.

BRASIL. MINISTÉRIO DA SAÚDE. Conselho Nacional de Saúde. CNS/MS (Brasil). Resolução no 466/2012, 12 de dezembro de 2012. Aprovar as seguintes diretrizes e normas regulamentadoras de pesquisas envolvendo seres humanos. Diário Oficial da União 13 jun. 2013.

CARREIRA, Suely da Silva et al. Empreendedorismo feminino: um estudo fenomenológico. Navus, Florianópolis, v. 5, n. 2, p. 06-13, 2015. Disponível em: http://navus.sc.senac.br/index.php/navus/article/view/208. Acesso em: 15 fev. 2020.

CARVALHO, Deciane Pintanela de et al. Entrepreneurial characteristics of nurses: a study in southern brazil. Revista Baiana de Enfermagem, Salvador, v. 30, n. 4, p. 1-11, out./dez. 2016 https://pdfs.semanticscholar.org/06df/811f14626b959ed70808e7eec62796c4be45.pdf. Acesso em: 25 de mai. 2020. 
CASTRO, Marcia C et al. Brazil's unified health system: the first 30 years and prospects for the future. The Lancet. Published, v. 13, n. 2, 2019. Disponível em: https://fgvsaude.fgv.br/sites/gvsaude.fgv.br/files/18tl6929 atun final.pdf. Acesso em: 26 de mai. 2020.

CHAGAS, Sabrina de Cássia et al. O empreendedorismo de negócios entre enfermeiros. Rev enferm UERJ, v. 26, p. e31469, nov., 2018. Disponível em: https://www.epublicacoes.uerj.br/index.php/enfermagemuerj/article/view/31469/27757. Acesso em: 24 de mai. de 2020.

COLICHI, Rosana Maria Barreto; LIMA, Silvana Andrea Molina. Empreendedorismo na enfermagem: comparação com outras profissões da saúde. Rev. Eletr. Enf. [Internet], v. 20, n. 20, p. $11,2018.2$ Disponível em: https://www.revistas.ufg.br/fen/article/view/49358/25926. Acesso em: 26 de mai. 2020.

COPELLI, Fernanda Hannah da Silva; ERDMANN, Alacoque Lorenzini; SANTOS, José Luís Guedes dos. Entrepreneurship in Nursing: an integrative literature review. Rev Bras Enferm [Internet], v. 72, (Suppl 1), p. 289-98, 2019. Disponível em: https://www.scielo.br/pdf/reben/v72s1/pt 0034-7167-reben-72-s1-0289.pdf. Acesso em: 26 de mai. 2020.

COSTA, Fabiana Gallo et al. Tendências empreendedoras dos enfermeiros de um hospital universitário. Rev Gaúcha Enferm, v. 34, n.2, p.147-154, 2013. Disponível em: http://www.scielo.br/scielo.php?script=sci abstract\&pid=S1983-

14472013000300019\&lng=pt\&nrm=iso. Acesso em: 30 de out. 2018.

FIORIN, José Luís. Elementos de análise do discurso. 13. ed. São Paulo: Contexto, 2005.

JAHANI, Simin et al. Iranian entrepreneur nurses' perceived barriers to entrepreneurship: A qualitative study. Iran J Nurs Midwifery Res, v. 21, n. 1, p. 45-53, 2016. Disponível em: http://www.jinmrjournal.net/text.asp?2016/21/1/45/174749. Acesso em: 26 de mai. de 2020

MINAYO, Maria Cecília de Souza. O Desafio do conhecimento: pesquisa qualitativa em saúde. 10. ed. São Paulo: Hucitec/Abrasco, 2007. p.406.

MOURA, Jade de Medeiros; BRUM, Zaléia Prado de. A enfermagem do ponto de vista empreendedor. Revista Interdisciplinar em Ciências da Saúde e Biológicas, v. 1, n. 1, 
p.11-19,

2017.

Disponível

em:

http://srvapp2s.santoangelo.uri.br/seer/index.php/RICSB/article/view/2483/1088. Acesso em 25 de mai. de 2020 .

POLAKIEWICZ, Rafael Rodrigues et al. Potencialidades e vulnerabilidades do enfermeiro empreendedor: uma revisão integrativa. Perspectivas Revista Biologia e saúde Campos do Goytacazes, v.11, n.3, p.53-79, 2013. Disponível em: http://www.seer.perspectivasonline.com.br/index.php/biologicas e saude/article/view/14/10 25. Acesso em: 30 out. 2018.

RIBEIRO, Maria Isabel et al. Empreendedorismo, inovação e desenvolvimento local: as micro e pequenas empresas do interior norte de Portugal. Revista de Empreendedorismo e Gestão de Micro e Pequenas Empresas, v.1, n3, p.34-53, Mai./Jun., 2016. Disponível em: https://bibliotecadigital.ipb.pt/handle/10198/13745. Acesso em: 24 out.2018.

SILVA, Ana Cristina da Paixão; VALENTE, Gabriel Luis Cavalcanti; VALENTE, Geilsa Soraia Cavalcanti. Entrepreneurship as a tool for the nurse's work. Revista de Enfermagem UFPE, v.11, n. 4, p. 1595-602. 2017. Disponível em: http://bases.bireme.br/cgibin/wxislind.exe/iah/online/?IsisScript=iah/iah.xis\&src=google\&base =BDENF\&lang=p\&nextAction=Ink\&exprSearch=31204\&indexSearch=ID. Acesso em: 24 out. 2018.

VITAL, Hudson Filipe; AMA, Pamella Berbe; ASSIS, Marco Antônio de. Enfermagem e empreendedorismo: principais fatores que envolvem o profissional em sua perspectiva na prática assistencial. Revista Científica UMC Edição Especial PIBIC, v. 3, n. 3, Out. 2018. Disponível em: http://seer.umc.br/index.php/revistaumc/article/view/533/426. Acesso em: 30 jan. 2020.

\section{Agradecimentos}

Agradecimentos especiais aos alunos que se dispuseram a participar desta pesquisa. 